\title{
The Training of Cross-cultural Communicative Competence of College English Majors in the Context of New Media Communication
}

\author{
Xu Xueyan \\ Hubei University of Traditional Chinese Medicine, Wuhan, Hubei 430065, China
}

Keywords: new media; communication environment; College English majors; cross-cultural communication ability; training strategy

\begin{abstract}
In the context of the information age, with the rapid development of social economy, the new media industry has risen rapidly and the new media has become more diversified. At present, in the English major of colleges and universities, although the students have experienced long-term and systematic English learning, the intercultural communication ability is still low. Under the new media communication environment, College English teaching should not only pay attention to the transfer of basic language knowledge, but also pay attention to cultivating students' intercultural communicative competence in order to enhance students' creativity and enthusiasm for English learning, and thus improve students' comprehensive English level and practical application ability.
\end{abstract}

\section{Introduction}

In recent years, the rapid development of the new media industry has changed the mass media communication mechanism, and has also brought a greater impact on social life, ushering in a micro-era. Under the background of this era, the spread of new media has shortened the spatial distance between people, has brought a greater impact on traditional life and work methods, and has also affected the field of higher education teaching, breaking its traditional teaching model [1]. With the continuous promotion of the teaching reform of English majors in colleges and universities, the new media technology is widely adopted in English teaching. The English teaching mode is constantly adjusted according to the teaching goals, and the cross-cultural communication ability of students is also cultivated. Under the new media communication environment, the ability to cultivate cross-cultural communication among English majors in colleges and universities is mainly through the diversified transmission channels of new media, creating a good learning environment for students, activating students' thinking in English, and improving their practical ability in communicative competence and English are crucial for students.

\section{The Role of New Media in Cross-cultural Communication}

New media is a new form of communication media that facilitates exchanges between countries and nations and has a strong impact on traditional media. In the context of the new media era, cross-cultural communication has undergone a transformation between audiences, content, and 
communicators, which has expanded the scope of intercultural communication and increased the scope of communication. In cross-cultural communication, new media is often considered as an important technology platform for creating a social environment. It is mainly a kind of communication media that develops with the development of multimedia technology, computer network technology, and digital technology, such as WeChat and Micro-blog, QQ and other social software provide technical support for individual development and social communication, facilitate understanding and communication between different cultural differences, and promote cultural diversity [2]. In addition, the new media fully plays the role of the teaching system in the teaching of cross-cultural communication in colleges and universities. In the context of the new media era, the teaching reform of colleges and universities continues to deepen. In the teaching process, new media are used to build a teaching and information dissemination platform, which makes the teaching process more ideal and more efficient. In the era of new media, it is very important to cultivate students' multiple reading and writing abilities. Some linguists have proposed the ability to use multiple reading and writing capabilities, ie, the use of network materials, and the use of network technologies in network environments. Through online interaction, students' critical thinking and cooperation ability can be effectively improved, so as to realize cross-cultural awareness of students. Therefore, in the teaching of English majors in colleges and universities, the application of new media technologies has provided new opportunities for teaching work, is conducive to the realization of teaching goals, and plays an important role in cultivating and improving students' intercultural communicative competence.

\section{Key Points for Improving Students’ Intercultural Communication Skills}

\subsection{Fully consider the objective language environment and human environment}

In interpersonal communication, in order to ensure the effectiveness of the communication process, it is necessary to have a certain degree of communicative competence, that is, to fully understand the speaker's intention in a specific language environment, and to use it as a guide for their own actions, but in actual communication activities, we must fully consider the objective language environment and the human environment. In cross-cultural communication, influenced by linguistic habits and objective conditions, it is necessary to understand the language environment from the cultural level, improve the ability of cross-cultural communication, consider man-made situations, and improve people's ideological consciousness in an artificial context. In the social field, it is necessary to develop booking habits when dealing with British and American people. This is a basic courtesy behavior for British and American people. If you are invited to dine in English and Americans, you need to note that the arrival time cannot be advanced and should be reached on time [3]. For example, in the field of education and teaching, the classroom teaching atmosphere in the United States and the United States is free and active. However, Chinese teachers are stricter in their requirements for students' behaviors in class. In the communication, the two parties do not feel the same in each other's behavior. Therefore, cross-cultural communication needs not only to fully understand each other's language and culture, but also to understand the value of the culture, so as to promote the smooth conduct of cross-cultural communication.

\subsection{Attention to empathy}

Empathy plays a crucial role in cross-cultural communication. Empathy is the way of thinking through transposition and experiencing its experiences and ideas from the other side in the process of communication. This requires the speaker to use a positive attitude to understand each other's emotions, control their emotions, and avoid extremes. In addition, you can also interpret each 
other's logical thinking through empathy. Empathy helps to compare and understand the differences and commonalities of the values of the two parties.

\subsection{Use dialogue to communicate}

In cross-cultural communication, dialogue is a basic form of behavior that respects and recognizes each other, and can effectively increase the degree of interdependence between the two sides. Dialogue can promote dynamic integration between the two parties while retaining their own personalities. The dialogue makes all members of the communication activities not to be neglected, but at the same time it will not be fully integrated, and conflicts can be effectively resolved in cross-cultural communication. When there are various factors of uncertainty in the communication, such as ethnic self-confidence, cultural prejudice, etc., the dialogue can be used to solve the problem. In communication, both parties can hold their own positions to communicate, and do not hide their own personality and characteristics, and give full play to the timeliness of cross-cultural communication.

\section{Strategies for Cultivating Students' Intercultural Communicative Competence in the Context of New Media Communications}

\subsection{Pay attention to knowledge education and cultural awareness}

The new media communication environment can effectively increase the interest and attractiveness of English teaching in college English classroom teaching, build a teaching system, and create a good learning atmosphere for students. Cross-cultural teaching is not only a theoretical linguistic knowledge teaching, but should also improve students' understanding and common emotion by analyzing the unique customs, historical and literary characteristics of different countries, and conducting cultural simulations and major event discussions. Enhance students' intercultural communication skills. In cross-cultural communication, effective communication is based on mutual understanding of the cultures of both sides, which can ensure a pleasant conversation between the two parties [4]. For example, in the film language, contextual information is very rich, creating an ideal situation for students' language learning. In English teaching, movie language can be used as the main visual material. Teachers should make full use of the BBC documentary, foreign language soundtracks, American dramas, and British dramas to compare cultural information in film and television language with domestic culture. Understand the cultural differences between different countries, thus creating a deep understanding of cultural differences and their connotations. In addition, it is also possible to use the self-media platform to carry out the activities of the original co-reading, and allow students to express their feelings in the Western classics reading process through various means such as praising, commenting, and voting. For English majors in colleges and universities, building a pure English language environment in English learning can effectively foster intercultural communicative competence.

\subsection{Make full use of multimodal teaching}

Under the new media communication environment, English teaching in colleges and universities must also strengthen the innovation of teaching methods. This is also the requirement of English subject teaching reform. In the English professional classroom, teachers should create a diversified learning environment for students and make full use of multimodal teaching. That is, they should make full use of multimedia technologies such as PPT in the classroom teaching process, and multi-modes such as network, video, audio, and written materials. That is, in the course of 
classroom teaching, multimedia technology such as PPT is fully utilized, and multi-modal teaching methods such as network, video, audio, and written materials are used to develop compound teaching, so that the teaching content is more diversified, and the students produce multi-sensory and all-encompassing experience and understanding [5]. In the actual teaching process, teachers should make full use of new media technologies to organize teaching activities. For example, in oral English teaching, students should independently select topics of interest, and give full play to their imaginations to create scenes in groups. Co-record short videos and upload them to class groups to facilitate learning and sharing among classmates. In reading teaching, students are allowed to draw mind maps according to the structure of the articles they read or read, clearly demonstrating the context of the articles. For some institutions with strong economic strength or joint ventures of Chinese and foreign countries, it is possible to carry out cross-class class-pairing activities to achieve online cross-cultural communication in the classroom through instant messaging software so that students can learn more about the English language countries. The cultural connotation and customs and habits of the students fully stimulate students' interest in learning from cross-cultural knowledge, increase their enthusiasm for cross-cultural learning, and develop students' intercultural communicative competence [6].

\subsection{Improve teachers' own cross-cultural communication skills}

In the teaching process of college English majors, teachers are the main implementers and mentors of students' cross-cultural communication ability training. The teachers' own cross-cultural communicative competence and cross-cultural sensitivity will directly affect the effectiveness and quality of students' cross-cultural communicative competence training. At present, in the process of cultivating students' intercultural communicative competence, some teachers have failed to accurately grasp the concept of cross-cultural communicative competence and have not focused on explaining and supplementing the cultural knowledge involved in English language countries in classroom teaching, cause students to learn less about their culture, lack of interest in language learning [7]. In the context of new media communications, although college English disciplines have adopted new media technologies in teaching, some teachers have seldom used new media to demonstrate the communication between China and different English language countries in the classroom. Without the use of foreign teachers from English-speaking countries to conduct online or offline courses, the students' cross-cultural communicative competence is not ideal. For this reason, in the process of cultivating intercultural communicative competence of English majors in colleges and universities, teachers should also fully study the theoretical knowledge of cross-cultural teaching and strengthen communication practice, and learn about the cross through various ways such as focusing on Micro-blog and subscribing to the WeChat public number. Cultural communication knowledge and communication skills, using mobile phone APP to communicate and learn online with foreign friends, and in the actual teaching through various types of teaching methods and online learning methods such as MOOC, micro lessons and so on to improve the teachers' self-cultivation level of cross-cultural communication, and actively participated in the process of formulating the syllabus for cross-cultural communication courses, developed effective communicative competence testing systems, improved their intercultural communicative competence, and discussed and extended the content of cross-cultural communication courses with students in class [8].

\section{Conclusion}

All in all, under the informational background environment, the new media industry is represented by Internet technology, integrated multimedia technology, network technology, 
information technology, etc., to break the space-time restrictions between people and use new media technologies to achieve the exchange process. In the rapid development of new media products, the speed of media dissemination has accelerated, and the interaction modes have been continuously integrated, providing new opportunities for the development of cross-cultural communication. Under the new media communication environment, English majors in colleges and universities must not only improve their English theoretical knowledge, but also improve their intercultural communicative competence and master the cultural connotation and cultural background of other countries in order to achieve effective communication. In English teaching, teachers should make full use of social media and cultural products to disseminate channels, develop students' intercultural communicative competence in three aspects of behavior, emotion and cognition, improve students' intercultural communication skills, and achieve global information sharing.

\section{References}

[1] ZHANG Liman, CHANG Huijuan, ZHOU Hongying, BAI Yu. International Chinese teachers' cross-cultural communicative competence training_based on the investigation of the establishment of cross-cultural communicative courses in 40 colleges and universities [J]. Journal of Heilongjiang Institute of Technology (Comprehensive Edition), 2017, 17(05):35-39.

[2] Lu Kui, Li Yingxue, Zhang Rongfang. Study on the Cultivation of Intercultural Communication Ability of Students in Higher Vocational Colleges under the Background of Work-Study [J]. Xingtai Vocational and Technical College, 2017, 34(02):10-13+17.

[3] JIN Guitao, LIU Chang, CHENG Zongying. Current status and training strategies of undergraduates' cross-cultural communication competence under the "One Belt and One Road" strategy [J]. Journal of Naval University of Engineering, 2017, 14(01): 83-87.

[4] Chen Xinren, Li Jie. On the Cultivation of Cross-cultural Communication Ability under the Background of English as an International Language [J]. Contemporary Foreign Languages Studies, 2017(01):19-24.

[5] Tian Hao. Cross-cultural communication and cultural consciousness in the context of globalization [J]. Journal of Xidian University (Social Sciences), 2015, 25(02):122-126.

[6] Tong Wei. A study of non-English major college students' cross-cultural communicative competence in a global perspective [J]. Journal of Jilin Provincial Institute of Education (middle), 2013, 29(01):23-25. 